\title{
A INSCRIÇÃO DA MADONNA NEGRA
}

\author{
Dárcio Roberto Martins Rodrigues \\ Professor Doutor do Departamento de Direito Civil da Faculdade de \\ Direito da Universidade de São Paulo
}

\begin{abstract}
Resumo:
Notando uma muito curiosa ligação entre uma inscrição latina encontrada em um santuário medieval no Sul da Itália e um recente caso de racismo no Brasil, o autor deste artigo pesquisa a origem histórica daquela epígrafe e chega a interessantes conclusões sobre os seus muitos aspectos lingüísticos, jurídicos e religiosos, bem como a uma digressão acerca da questão do racismo na cultura brasileira.
\end{abstract}

\begin{abstract}
:
Finding a very peculiar connection between a Latin inscription in a medieval shrine in South Italy and a recent case of racism in Brazil, the author of this essay traces back the historical origin of that epigraph, which leads to interesting conclusions as to its many linguistic, legal and religious implications, as well as to a digression on the question of racism in Brazilian culture.
\end{abstract}

Unitermos: racismo; latim; Bíblia.

Em setembro de 1997, o professor Eduardo Marchi — titular de Direito Romano da nossa velha e sempre nova Academia de Direito do Largo São Francisco - viajou à Itália, a fim de participar, na cidade de Messina, na Sicília, do $51^{\circ}$ congresso anual da "Societé Internationale Fernand De Visscher pour L'Histoire des Droits de L'Antiquitè" (SIHDA). Aproveitando um raro momento de folga entre as intensas atividades do congresso, decidiu visitar Tindari, antiga cidade grega na atual província de Messina. Nessa localidade existe um antigo santuário cristão, onde o professor Marchi pode observar uma madonna negra, na qual se lê a seguinte inscrição: "Nigra sum sed formosa" (sou negra, mas formosa). 


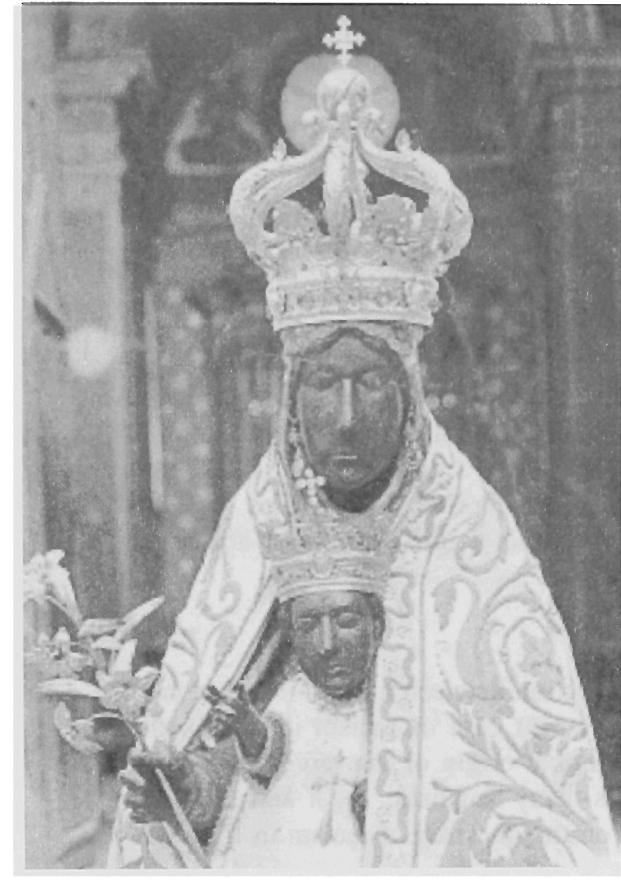

A madonna negra de Tindari.

Sendo um bom conhecedor de história da arte, nãoestranhou o fato de ser negra a estátua da madonna, ocorrência nada inusitada em imagens medievais e bastante conhecida dos estudiosos da arte sacra. De fato, existem hoje centenas de imagens negras da madonna em várias partes do mundo, das quais podemos citar, entre as mais famosas, as que se encontram nos santuários de Altotting (na Baviera, Alemanha), Jasna Gora (em Czestochowa, Polônia), Montserrat (Espanha), Guadalupe (México) e Einsiedeln (Suíça); ${ }^{1}$ aqui mesmo no Brasil a famosa imagem por tantos cultuada na cidade de Aparecida do Norte é, na verdade, uma madonna de cor negra. A adoração de representações da maternidade em cor negra é um fenômeno muito antigo e comum na história das religiões, tendo sido descobertas esculturas negras de Ísis, Ceres e outras deusas da Antigüidade. Sobretudo Ceres (a deusa romana da agricultura) e Deméter (sua equivalente grega) são importantes nesse contexto, já que se acredita que tais imagens negras se originaram do primitivo culto

1. Esta última é, talvez, um exemplo enganoso, pois em verdade se tratava, originalmente, de uma madonna branca, a qual sofreu escurecimento em razão de fatores físico-químicos que atuaram sobre a sua pigmentação ao longo dos séculos. Embora não seja ocorrência tão freqüente, o estudo da iconografia religiosa registra outros casos semelhantes, sobretudo em se tratando de imagens que foram salvas de santuários ou igrejas incendiados, tendo a fumaça e as chamas escurecido as estátuas. Para uma lista detalhada de santuários com madonne negras, consultar: BEGG, Ean C. M., The Cult of the Black Virgin, Boston, Arkana, 1985. Mas ver também a bibliografia da nota 2 infra. 
à fertilidade da terra. Tudo indica que a veneração de madonne negras resultou da recepção e assimilação desses cultos antigos pelo cristianismo ainda incipiente. ${ }^{2}$

Causou-lhe estranheza, no entanto, a inscrição, que parecia trair um sentimento latente de preconceito étnico. Meditando sobre o assunto, o professor Marchi considerou que, se fosse feita no Brasil e nos dias de hoje, uma tal estátua com semelhante inscrição poderia até mesmo levar o seu escultor a uma condenação pelo crime imprescritível e inafiançável de racismo.

De fato, o art. $5^{\circ}$ : XLII, da Constituição Federal reza: "a prática do racismo constitui crime inafiançável e imprescritível, sujeito à pena de reclusão, nos termos da lei" E o art. 20 da Lei n. 7.716, de 05 de janeiro de 1989 (com redação dada pela Lei n. 9.459, de 13 de maio de 1997) assim regulamentou o tipo penal: "Praticar, induzir ou incitar a discriminação ou preconceito de raça, cor, etnia, religião ou procedência nacional. Pena: reclusão de 1 (um) a 3 (três) anos e multa'.

De volta ao Brasil, Eduardo Marchi comentou o caso da madonna negra com vários amigos e colegas, inclusive pessoas de notória erudição e bom conhecimento das tradições religiosas cristãs. Nenhuma delas fez qualquer observação especial sobre a misteriosa inscrição. Curiosamente, foi o jovem mestrando Eduardo Del Nero Berlendis, fervoroso leitor da Bíblia, quem de pronto reconheceu e corretamente identificou essa citação, retirada do Antigo Testamento (Cântico dos Cânticos, 1: 5), e que, na tradicional tradução portuguesa de João Ferreira D'Almeida, ${ }^{3}$ aparece da seguinte forma:

${ }_{5}$ Morena sou, porém aprazível, ó filhas de Jerusalém, como as tendas de Kedar, como as cortinas de Salomão.

2. Para uma ampla fundamentação ver, principalmente, os mais importantes estudos recentes: Benko, Stephen, The Virgin Goddess: Studies in the Pagan and Christian Roots of Mariology, Nova York, E.J. Brill, 1993; e Birnbaum, Lucia Chiavola, Black Madonnas, Boston, Northeastern University Press, 1993.

3. Aqui citada conforme a edição de 1948 das Sociedades Bíblicas Unidas, Rio de Janeiro. Foi pela tradução de João Ferreira D'Almeida que o solerte Eduardo Berlendis reconheceu a frase bíblica. 
O texto português fala em morena e não negra, o que está em consonância com a explicação que vem no versículo seguinte:

${ }_{6}$ Não olheis para o eu ser morena; porque o sol resplandeceu sobre mim: os filhos de minha mãe se indignaram contra mim, puseram-me por guarda de vinhas (...).

A tez escura da protagonista é aqui perfeitamente elucidada. Não se trata, como se vê, de uma mulher negra, mas sim bronzeada de sol, em razão de ter sido designada para guardar vinhas, trabalho árduo realizado ao ar livre.

O acontecimento despertou-nos a curiosidade na ocasião, mas não pareceu ter nada de extraordinário, salvante a espantosa perspicácia do amigo Berlendis, que reconheceu de imediato uma citação bíblica pouco conhecida, e apesar da fraseologia ligeiramente distinta que se encontra na versão em português.

Não teríamos mais pensado no caso, não fosse um incidente noticiado nos jornais cerca de três meses mais tarde, em janeiro de 1998. Naquela ocasião nos encontrávamos na cidade de Köln, na Alemanha, onde desenvolvíamos um projeto de pesquisa, e só tomamos conhecimento do fato graças, mais uma vez, ao professor Marchi, que nos guardou um recorte da edição de 10 de janeiro de 1998 do jornal Folha de S. Paulo. Nessa edição, à página 8 do caderno 3 encontra-se a manchete: "Questão de vestibular é considerada racista". Os detalhes da história se referiam à seguinte questão, constante da então recente prova de língua portuguesa do vestibular da Universidade Federal de Mato Grosso do Sul: 
"09- Examine as orações dos períodos $\boldsymbol{a}$ e $\boldsymbol{b}$ abaixo $e$ assinale a(s) alternativa(s) correta $(s)$ :

a Ela é bonita, mas é negra.

b Embora negra, ela é bonita.

(01) Os periodos apresentam estrutura sintática diferente.

(02) Em a, a cor da moça é argumento desfavorável à sua beleza.

(04) Em b, a cor da moça é uma restrição superável pela beleza.

(08) Em a há coordenação; em $\boldsymbol{b}$ há subordinação.

(16) O valor argumentativo das proposições é diferente."

A notícia informava que a inclusão dessa questão na prova causou grande celeuma entre as entidades representantes da minoria negra, que a consideraram racista e se insurgiram contra a UFMS. O ICAB (Instituto e Casa de Cultura Afro-Brasileira) decidiu ingressar com uma representação criminal junto ao Ministério Público Federal e registrar a notitia criminis na Secretaria Pública, com base na supracitada Lei n. 7.716/89. Também o Grupo Tez (Trabalhos e Estudos Zumbi) resolveu pedir a anulação da questão e uma retratação pública da Universidade, não descartando a possibilidade de uma ação judicial contra a mesma. O acontecimento trouxe aborrecimento até para o Ministro da Educação, Paulo Renato de Souza - que lamentou em público a inclusão da dita questăo no vestibular - e muito constrangeu o reitor da UFMS, Jorge João Chacha, o qual com certeza não teve participação alguma na preparação da questão, mas se viu obrigado a despachar uma nota oficial pedindo "desculpas à sociedade"

Com grande surpresa verificamos que a "profecia" do professor Marchi se realizara: por uma curiosíssima coincidência, alguém havia utilizado, no Brasil, quase exatamente a mesma frase encontrada no pedestal da madonna negra, e, tal como Eduardo Marchi havia imaginado, isso suscitava agora um possível processo criminal por delito de racismo. 
Esses eventos reacenderam em nós o interesse pela singular citação bíblica, e nos trouxeram muitas indagações, não tanto acerca do seu significado religioso, mas principalmente da sua aparente carga subjacente de discriminação racial. Pusemo-nos a imaginar como esse versículo pôde ter sido pacificamente aceito ao longo de tantos séculos por leitores cristãos e judeus - mormente por terem sido estes últimos desde sempre vítimas, eles mesmos, de toda sorte de preconceitos e perseguições raciais. Questionávamos, ainda, por que o texto de João Ferreira D'Almeida falava em "morena" em vez de "negra" Teria o tradutor português simplesmente alterado e deformado o texto bíblico a fim de encobrir uma embaraçosa referência discriminatória? Ou teria sido, ao contrário, o escultor da madonna negra o responsável por essa fraseologia de conotação racista?

Cumpre salientar aqui que o autor destas linhas não é teólogo, nem tem pretensão alguma de arvorar-se em exegeta de textos sacros. Entretanto, como jurista e sobretudo romanista de formação, está habituado a trabalhar com textos antigos e estudar a sua recepção ao longo dos séculos. Assim sendo, e a fim de encontrar a resposta àquelas indagações, decidimos consultar diretamente o texto da Vulgata, de onde a inscrição da madonna negra, pelo que se vê, foi retirada, e encontramos o seguinte:

4 nigra sum sed formonsa filiae Hierusalem sicut tabernacula Cedar sicut pelles Salomonis

5 nolite me considerare quod fusca sim quia decoloravit me sol (...). ${ }^{4}$

Vemos, então, que a inscrição na madonna negra é apenas uma literal transcrição do latim da Vulgata, a qual já há quatro séculos apresentava quase ipsis litteris a malsinada frase que tanta celeuma veio causar no vestibular da UFMS.

4. Biblia Vulgata, edição crítica de Roger Gryson, Stuttgart, Deutsche Bibelgesellschaft, $4^{a}$ ed.,

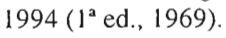


Aparece, pois, a palavra nigra no quinto versículo do Cântico dos Cânticos, ${ }^{5}$ embora o sexto apresente o termo fusca, de igual significado, mas também com a possível conotação de "moreno ou amulatado, trigueiro" 6 em particular com o sentido de "bronzeado pelo sol" 7 O que é atestado, por exemplo, pela ocorrência da palavra no seguinte verso de Tibulo:

Illi sint comites fusci, quos India torret, (Tibull. $2,3,55)$

Ou seja, depreende-se que os "comites" são "fusci" porque são abrasados pelo sol da Índia ("quos India torret"). O mesmo sentido foi empregado na Vulgata: "fusca sim quia decoloravit me sol" Confirma-se de modo patente, em vista disso, que o adjetivo "nigra" no versículo anterior não pretendia aludir à raça negra, mas sim à pele escurecida por efeito do bronzeamento pelo sol.

Nossa curiosidade foi aguçada ainda mais por essas descobertas. Pois nos pusemos então a indagar por que São Jerônimo teria empregado na Vulgata o vocábulo "nigra" em vez do termo latino "adustus" que propriamente significa "queimado de sol": 8 ou outro termo semelhante, a exemplo do próprio "fuscus" encontrado no versículo seguinte.

5. Enumerado como 4 na Vulgata cf. a edição crítica de Roger Gryson, que utilizamos como base da nossa citação, nota 4 sıpra. A razão da diferente numeração se explica pelo fato de que as palavras tradicionalmente apresentadas como versículo primeiro correspondem na verdade ao título do livro, engano devidamente corrigido na edição de Gryson.

6. Cf. Saraiva, F. R. dos Santos, Dicionário Latino-Portıguês, $10^{\mathbf{a}}$ ed., Rio de Janeiro, Garnier, 1993 (fac-símile da $9^{a}$ ed. de 1927).

7. Cf. Schönberger, Otto, Lateinische Synonimik, $7^{\mathrm{a}}$ ed., Heidelberg, Carl WinterUniversitätsverlag, 1988 , p. 197 , n. 346 , que, embora admitindo tratar-se de termos sinonímicos, explica a sutil diferença semântica entre "niger" ("tief schwarz, glänzend schwarz") e "fuscus" ("schwarzbraun, schwarzrau", ou ainda "von der Sonne geschwärzt").

8. Cf. e.g. em Tito Lívio, descrevendo o modo pelo qual Asdrúbal buscou averiguar se as tropas romanas tinham recebido reforços:

misit ad flumen unde aquabantur ubi et excipi aliqui possent at notari oculis si qui forte adustioris coloris ut ex recenti uia essent;

(Livius, Ab Urbe Cond., 27,47, 3). 
É bem verdade, e não o negamos, que o adjetivo "niger" em latim, quando referido a pessoas, admite também a conotação de "moreno" não necessariamente "negro" A autoridade incontestável do monumental dicionário Oxford" referenda para "niger" a possível significação de "having a dark skin or complexion, swarthy, dusky" oferecendo também quase idêntica tradução para os termos "fuscus" e "adustus" Tal entendimento é comprovado por citações à literatura latina, sendo notável sobretudo esta de Ovídio, segundo o qual um marinheiro deve ser moreno ("niger") em razão de ficar exposto aos raios solares ("a radiis sideris"):

Candidus in nauta turpis color, aequoris unda Debet et a radiis sideris esse niger.

(Ovid., Ars Amat. 1, 723-724)

Vê-se que o poeta chama de "niger" a pele rude da gente do mar, maltratada pelo sol ("radiis sideris") e pela água salgada do mar ("aequoris unda"). É igualmente notável observar que o próprio Ovídio atesta, em outros versos, o uso pejorativo de tal adjetivo para descrever as moças de pele amorenada, característica estética pouco apreciada entre os romanos:

Qua potes, in peius dotes deflecte puellae, Iudiciumque brevi limite falle tuum.

Turgida, si plena est, si fusca est, nigra vocetur.

(Ovid., Rem. Am. 325-327)

O general cartaginês supôs que, se reforços tivessem chegado recentemente ("ex recente via"), a pele dos soldados teria sido banhada pelo sol durante a longa marcha e apresentaria coloração mais bronzeada ("adustioris color"). De resto, é evidente a derivação etimológica desse adjetivo a partir do verbo "urere" ("queimar", scil. de sol).

9. Glare, P. G. W. (org.), Oxford Latin Dictionary, Oxford, Clarendon Press, 1982 (reimpr. com correções 1996). 
O poeta recomenda, para detração da "puella". seja ela chamada "nigra", se for morena ("fusca").

Com isso, fica estabelecido que não-chega a haver impropriedade no uso do vocábulo "nigra" no referido versículo da Vulgata, tanto mais que nele a camponesa se refere à cor da própria pele em sentido claramente depreciativo. Ainda assim, ficamos a imaginar por que motivo teria sido preferido esse termo àqueles outros ("fusca" ou "adusta"), mais diretos e inequívocos.

É sabido que São Jerônimo utilizou o texto original hebraico na sua tradução do Antigo Testamento (com exceção dos salmos, para os quais teria feito apenas uma revisão da Vetus Latina). ${ }^{10}$ Mas também é inconteste que ele tinha conhecimento da tradução dos Septuaginta, tendo-a consultado para confronto durante os seus trabalhos. Pelo impulso da curiosidade, ousamos levar mais longe a nossa investigação, buscando o texto dos Septuaginta, onde se lê:

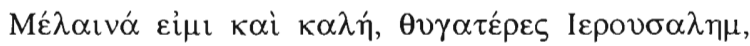
$\dot{\omega} \varsigma \sigma \kappa \eta v \omega ́ \mu \alpha \tau \alpha \mathrm{K} \eta \delta \alpha \rho, \dot{\omega} \zeta \delta \varepsilon \rho \rho \varepsilon \iota \varsigma \Sigma \alpha \lambda \omega \mu \omega v^{11}$

Já está aí, portanto, o vocábulo $\mu \varepsilon ́ \lambda \alpha \iota v \alpha ́$, que significa mesmo "negra" É, porém, significativo um outro detalhe que nos chama a atenção: o uso da conjunção aditiva $\kappa \propto$ ("e"), que parece dar um sentido menos preconceituoso do que sed ("sou negra e bonita" em lugar de "sou negra, mas bonita"). Não nos escapa,

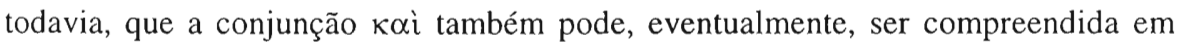
um sentido adversativo em construções como essa, sobretudo quando usada com particípios ou adjetivos (cf. Liddel-Scott). ${ }^{12}$ Não sendo nossa especialidade a língua

10. Feita por vários autores anônimos, essa antiga e primeira tradução do Antigo Testamento para o latim não constituiu obra original, sendo nada mais que uma versão da Septuaginta para o latim, acrescentando inúmeros defeitos e imprecisões aos que já havia no texto grego. Nesse sentido, a Vulgata foi de fato realização bastante oportuna.

11. Septuaginta, ed. A. Rahlfs, v. 2, Stuttgart, Wurttembergische Bibelan-stalt, 9ª ed., 1935 (reimpr. 1971).

12. Liddel, H. G. e Scott, R., Greek-English Lexicon, Oxford, Clarendon Press, 1996 (reimpr. da $1^{\text {a }}$ ed. 1891), que apresenta como exemplo uma construçāo semelhante, só que com o particípio, e

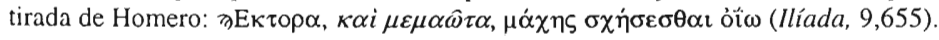


grega, deixamos aos colegas helenistas o exame deste tópico com vistas no versículo em tela. ${ }^{13}$ Mas trazemos à balha esse detalhe porquanto se revestirá de interesse mais adiante, quando será demonstrado que muitas traduções modernas da Bíblia optaram pela aditiva em lugar da adversativa.

Ocorreu-nos, em seguida, que seria assaz interessante procurar um rabino ou alguém na comunidade judaica que nos pudesse explicar como é o original em hebraico. Isso, porém, não chegou a fazer-se estritamente necessário. Não é, de fato, mister conhecer o idioma hebreu para proceder a uma tal pesquisa, graças ao excelente trabalho do erudito James Strong (1822-1894), que no final do século passado prestou inestimável serviço aos estudiosos do texto bíblico com a preparação do seu famoso Concordance. ${ }^{14}$ Trata-se de uma edição baseada no texto inglês da "Authorized Version" (ou "King James Version") da Bíblia, em rigoroso confronto com os originais em aramaico, hebraico e grego. Strong utilizou-se de um original sistema de numeração, pelo qual todas as palavras-chaves de cada versículo bíblico recebem um código numérico único, referido a um dicionário bíblico preparado pelo próprio Strong, que era profundo conhecedor daqueles idiomas. Por meio desse código, mesmo uma pessoa ignorante em língua hebraica está apta a identificar o vocábulo correspondente empregado no texto original e, não-somente lhe apreender o significado no dicionário de Strong, como também - o que é mais notável - localizar imediatamente todas as passagens da Bíblia nas quais aquele mesmo vocábulo hebraico aparecia no original.

Procurando na obra de Strong, verificamos que, embora a palavra "black" (negro) apareça dezoito vezes no texto inglês da King James Version, nem sempre esse termo traduz o mesmo vocábulo hebraico do texto original. No versículo dos Cantares de Salomão que presentemente nos interessa (Cant. 1:5), o termo "black" está assinalado por Strong com o número 7838 de seu Concordance. Esse número corresponde, segundo Strong, à palavra hebraica rxf ("shachor" Ishaw-

13. Em meio a tantas citações latinas, faz-se aqui bem azada, a esse propósito, mais uma: "Sutor, ne supra crepidam" - não queira o sapateiro opinar acima das sandálias!

14. Existem diversas edições modernas, por exemplo, Strong, James, The New Strong's Exhaustive Concordance of the Bible, Nashville, Thomas Nelson Publishers, 1990. 
khore'l) ou rwxf ("shachowr") que, ainda segundo Strong, é um adjetivo e significa "negro"

E, de fato, consultando uma edição do antigo testamento em hebraico, podemos encontrar, no versículo em estudo, a palavra indicada por Strong:

5 שחורה אני ו:נאוה בנוח ירושלם כ:אהלי קדר כ:יריעות שלמה

O mais revelador, no entanto, é que, conforme o Concordance de Strong, esse termo hebraico só ocorre outras cinco vezes em toda a Bíblia, a saber em: Lev. 13:31; Lev. 13:37; Cant. 5:11; Zac. 6:2 e Zac. 6:6. A leitura desses versículos em qualquer tradução do texto bíblico nos revela, pelo próprio contexto, e com meridiana clareza, que o emprego de "schaschowr" nas escrituras era sempre no sentido geral de "negro", só aparecendo com a conotação de "moreno" no estudado versículo de Salomão. As duas ocorrências no livro de Zacarias, por exemplo, se referem à cor de cavalos - negros - e o outro versículo no próprio livro do Cântico dos Cânticos diz respeito aos cachos de cabelos negros, os quais, muito significativamente, são comparados com a cor de um corvo:

Cant. 5:11 A sua cabeça é como o ouro mais apurado, as suas guedelhas crespas, pretas como o corvo. ${ }^{15}$

Disso se conclui que o termo correto e que mais fielmente reproduz o original em Cant. 1:5 é mesmo "negra" embora seja inequívoco que o sentido poético pretendido seja o de "queimada de sol" "morena" Tanto a Septuaginta quanto a Vulgata nada mais fizeram do que seguir com fidelidade o texto hebraico. Por alguma razão sua, o nosso tradutor português preferiu verter o texto mais livremente, pelo sentido contextual e conotativo da palavra, e não em seu rígido significado denotativo.

15. Na trad. de João Ferreira D'Almeida, cit. nota 3 supra. 
Nem com isso se viu saciada nossa curiosidade, pois outra questão assoma agora: como se comportaram as várias traduções modernas da Bíblia no tocante a esse versículo? Foram fiéis aos originais ou se portaram de modo semelhante ao do tradutor português?

A melhor e mais conceituada tradução inglesa, a "Authorized Version" popularmente conhecida como "King James Bible" por ter sido realizada sob os auspícios do rei James I no século XVII, ${ }^{16}$ apresenta o seguinte teor:

I am black, but comely, O ye daughters of Jerusalem, as the tents of Kedar, as the curtains of Solomon.

Segue, portanto, as mesmas expressões da Vulgata ("sou negra, mas formosa"). Desde quando publicado, em 1611, tem sido esse o texto bíblico universalmente aceito como padrão no mundo anglófono, sobretudo pela sua altíssima qualidade literária. A versão americana, revisada e emendada por Noah Webster no século passado, ${ }^{17}$ não alterou substancialmente o texto seiscentista, de um modo geral, e em particular no versículo em exame:

\section{I [am] black, but comely, $O$ ye daughters of Jerusalem, as the tents of Kedar, as the curtains of Solomon.}

Somente em 1881-1885, na Inglaterra, uma comissão realizou oficialmente uma revisão global da Bíblia do Rei James, mas o resultado, a chamada Revised Version, manteve absolutamente intocado o nosso versículo. Da mesma forma, em 1901 foi preparada, nos EUA, uma adaptação da Revised Version para a

16. A "Authorized Version" publicada em 1611, teve por base primeira a tradução iniciada um século antes pelo reformador William Tyndale. (Em 1525 Tyndale já havia publicado sua tradução do novo testamento diretamente do grego. Iniciou também tradução do antigo testamento a partir do hebraico, a qual, no entanto, ficou inacabada com a morte de Tyndale.)

17. The Holy Bible, New Haven, Durrie \& Peck, 1833. 
América, seguindo algumas preferências e particularidades dos estudiosos bíblicos norte-americanos. Surgiu assim a American Standard Version, que também não tocou em uma palavra sequer do já citado versículo de Salomão.

Mas, muito significativamente, e somente na segunda metade deste século, a Revised Standard Version ${ }^{18}$ emendou o texto para:

I am very dark, but comely, $O$ daughters of Jerusalem, like the tents of Kedar, like the curtains of Solomon.

Essa expressão "very dark" dá um sentido de "muito escura" ou "muito morena", mas não-negra. Seria muito interessante saber por que motivo os autores da RSV decidiram proceder a essa alteração. Considerando que a preparação dessa versão da Bíblia se deu pouco depois da Segunda Guerra Mundial, podemos imaginar que a inquietação com qualquer expressão que pudesse suscitar sentimentos raciais talvez estivesse particularmente exacerbada naquele momento. Lembremos ainda que as décadas que se seguiram à publicação da RSV foram marcados por conflitos étnicos e por intensa luta por direitos civis de minorias, sobretudo nos EUA.

Diante desse quadro, causa-nos surpresa, porém, verificar que a NRSV. ${ }^{19}$ realizada em 1989 , em tese uma simples revisão e atualização da RSV. apresentou o versículo com a seguinte textualidade:

I am black and beautiful, $O$ daughters of Jerusalem, like the tents of Kedar, like the curtains of Solomon.

18. Basicamente uma revisão da American Standard Version de 1901, publicada após a Segunda Guerra Mundial (Novo Testamento em 1946, Antigo Testamento em 1952).

19. New Revised Standard Version, copyright 1989, Christian Education of the National Council of the Churches of Christ in the United States of America. Realizada por um conselho ecumênico, recebeu aprovação oficial não só das variadas denominações protestantes, como ainda das igrejas católicas romana e ortodoxa. 
Como vemos, a NRSV retornou ao texto original, excluindo o "dark" e restaurando "black". mas introduziu uma inovação ao substituir a adversativa "but" por uma aditiva "and" Também trocou o "comely" por um sinônimo menos obsoleto e com isso, talvez sem querer, quase reafirmou o famoso slogan do "Black Power" americano: — "black is beautiful"!

Tal foi a evolução do texto original da versão do Rei James. Existem, porém, outras traduções para a língua inglesa. Tão-antiga quanto a "Authorized Version" ainda que não tão prestigiosa, é a tradução de Douay-Rheims, ${ }^{20}$ feita a partir da Vulgata. Essa versão também adota o "negra", como no texto latino, e também faz uso da adversativa:

I am black but beautiful, $O$ ye daughters of Jerusalem, as the tents of Cedar, as the curtains of Solomon.

Mais recentemente, a tradução de J. N. Darby, ${ }^{21}$ diretamente do original hebraico, manteve-se próxima da "Authorized Version":

I am black, but comely, daughters of Jerusalem, as the tents of Kedar, as the curtains of Solomon.

20. Assim chamada por ter sido iniciada sob os auspícios do English College em Douay (na França), fundado em 1568 pelo cardeal inglês William Allen (1532-94). O English College se tornou um reduto de vários intelectuais de Oxford que, sendo defensores do papismo, auto-exilaram-se quando do estabelecimento da Igreja anglicana. Encetaram em 1582 uma tradução da Vulgata com a finalidade de opor-se a e concorrer com a tradução do rei James, então em preparação. O Antigo Testamento foi publicado pela primeira vez em 1609. Essa tradução foi comumente adotada pelos católicos de língua inglesa até o início deste século, quando foi substancialmente revisada pelo bispo Richard Challoner. O texto que citamos é da edição de 1899 publicada em Baltimore por John Murphy $\&$ Co.

21. Publicada pela primeira vez em 1890. Citamos o texto de 1961, edição conjunta do Kingston Bible Trust, Lancing, Sussex (Inglaterra) e do Bible Truth Publishers, Addison. IL (EUA). De acordo com o prefácio dos editores, nada foi alterado da edição original, salvante notas de rodapé e detalhes de mera diagramação do texto. 
Por outro lado, a "tradução literal" de Young, ${ }^{22}$ ainda no século XIX, já havia preferido "dark" a "black" como a RSV. mas substituiu a adversativa ("but") por uma aditiva ("and"), acompanhando, neste particular, a NRSV:

Dark [am] I, and comely, daughters of Jerusalem, As tents of Kedar, as curtains of Solomon.

"Dark" foi também a solução adotada na NIV. ${ }^{23}$ uma nova tradução do original levada a cabo entre 1973 (novo testamento) e 1979 (antigo testamento) por uma comissão de intelectuais de vários países e representando várias denominações evangélicas, sob os auspícios da International Bible Society de Nova York:

Dark am I, yet lovely, O daughters of Jerusalem, dark like the tents of Kedar, like the tent curtains of Solomon.

Já a $\mathrm{NASB},{ }^{24}$ realizada em 1960 , com sua última revisão em 1995 , vertida em linguagem moderna e expurgada de arcaísmos, optou por manter o "negra" embora tenha substituído o "comely" por um adjetivo menos desusado, "lovely" (seguindo, portanto, nesse particular, o texto da NIV):

I am black but lovely, $O$ daughters of Jerusalem, Like the tents of Kedar, Like the curtains of Solomon.

22. Young's Literal Translation, Grand Rapids, Michigan, Baker Book House, 1898. Realizada por Robert Young no século passado, é uma tradução extremamente literal, que procura o mais possível manter o palavreado e os tempos verbais dos originais hebraicos.

23. The Holy Bible: New International Version by International Bible Society, Zondervan Publishing House, 1984.

24. New American Standard Bible, copyright by The Lockman Foundation, La Habra, Calif., 1960-1995. Não se trata de uma revisão da American Standard Version, mas de uma tradução inteiramente nova, diretamente dos originais em hebraico e grego. 
Isso com relação às traduções em língua inglesa. Vejamos agora o que aconteceu com o versículo em outros idiomas.

Na Alemanha, a tradução de Martin Luther, de $1534,{ }^{25}$ marco fundamental da literatura em língua alemã, assim apresenta o referido versículo:

Ich bin schwarz, aber gar lieblich, ihr Töchter Jerusalems, wie die Hütten Kedars, wie die Teppiche Salomos.

Notemos que a versão de Luther seguiu à risca a Vulgata, tanto no uso do termo "negra" ("schwarz") quanto na adversativa ("aber"). Mas é também muito interessante observar que a versão refundida pela igreja evangélica alemã entre 1957 e 1984 apresenta o seguinte texto: ${ }^{26}$

Ich bin braun, aber gar lieblich, ihr Töchter Jerusalems, wie die Zelte Kedars, wie die Teppiche Salomons.

Vemos que os revisores do texto de Luther optaram pelo termo "braun" (moreno, trigueiro, bronzeado) em lugar de "schwarz" (negro), mas mantiveram a adversativa "aber" Fizeram, portanto, em essência, a mesma alteração observada pelos revisores ingleses da Bíblia do Rei James.

25. Aqui apresentado segundo a versão revisada de 1914, cujo texto moderniza o linguajar arcaico do séc. XVI nos termos e expressões que hoje se tornaram obsoletos ou incompreensíveis, mas sem Ihes alterar a essência: Die Heilige Schrift, nach der deutschen Übersetzung D. Martin Luthers, neu durchgesehen (1914) nach dem vom deutschen evangelischen Kirche herauschuß genemihgten text, The British and Foreign Bible Society, 1950.

26. Die Bibel nach der Übersetzung Martin Luthers (revidierte Fassung), Stuttgart, Deutsche Bibelgesellschaft, 1985. O velho testamento foi concluído em 1964, os livros apócrifos em 1970 e o novo testamento em 1984. 
Da mesma forma, optou-se pelo "braun" na tradução suíça de Zwingli, $^{27}$ realizada no início deste século, entre 1907 e 1931, mantendo-se a adversativa com "doch":

Braun bin ich zwar, doch hübsch, ihr Töchter Jerusalems, wie die Zelte der Kedarener, wie die Zeltdecken der Salmärer.

O mesmo não ocorre, porém, na tradução de Elberfelder, ${ }^{28}$ que mantém o "schwarz" e enfatiza a adversativa com um "und doch":

Schwarz bin ich und doch anmutig, ihr Töchter Jerusalems, wie die Zelte Kedars, wie die Zeltdecken Salomos.

A tradução italiana, na versão oficial hoje adotada pela CEI (Commissione Episcopale Italiana), ${ }^{29}$ preferiu "bruna" (morena), mantendo, no entanto, a adversativa:

Bruna sono ma bella, o figlie di Gerusalemme, come le tende di Kedar, come i padiglioni di Salma.

Também a tradução espanhola de Casoidoro de Reina (1569), revisada por Cipriano de Valera (1602) e aqui apresentada na edição de $1960,{ }^{30}$ opta por "morena" em vez de "negra" e conserva a adversativa:

27. Cf. a edição de Zürich, Verlag der Zwingli-Bibel, 1942. Trata-se de uma nova tradução do original feita sob a égide do Kirchensynode e publicada pelo Kirchenrat do cantão de Zürich, na Suíça.

28. Revidierte Elberfelder Bibel, R. Brockhaus Verlag, 1985.

29. Disponível na Internet: http://www.crs4.it/riccardo/Letteratura/Bibbia/Bibbia.html 
Morena soy, oh hijas de Jerusalén, pero codiciable, como las tiendas de Cedar, como las cortinas de Salomón.

Pouca diferença apresentava a versão RVA na edição de $1909:^{31}$

Morena soy, oh hijas de Jerusalem, mas codiciable; como las cabañas de Cedar, como las tiendas de Salomón.

A tradução francesa de Louis Segon, ${ }^{32}$ por outro lado, manteve o "negra" e a adversativa, tal como na Vulgata:

Je suis noire, mais je suis belle, filles de Jérusalem, comme les tentes de Kédar, comme les pavillons de Salomon.

Ainda em língua francesa, a mais recente e respeitada tradução feita diretamente do hebraico parece ser a que se convencionou chamar "Bíblia de Jerusalém ${ }^{33}$ Concebida durante os anos da Segunda Guerra Mundial, foi realizada de 1945 a 1955 e publicada pela primeira vez, em versão integral, em 1956. O texto atualmente adotado recebeu uma revisão em 1973. Examinando o versículo que ora

30. Disponível na Internet: http://www.Isl.com.mx/ turbo/RVR/

31. Bíblia RVA, versão disponível na Internet em: http://bible.gospelcom.net/bible

32. Trad. de Louis Segon, publicada em 1910. Disponível na Internet: http://estragon.uchicago.edu/Bibles/BIBLE.form.html

33. Disponível na Internet, no site da editora Du Cerf, a mesma que patrocinou a publicação também sob a forma impressa: http://www.cerf-editions.com/bible.htm 
nos interessa, verificamos que, apesar da fraseologia e escolha de palavras ligeiramente diversas, mantiveram-se tanto o adjetivo "negra" quanto a adversativa:

Je suis noire et pourtant belle, filles de Jérusalem, comme les tentes de Qédar, comme les pavillons de Salma.

Muito peculiarmente, no entretanto, a versão em português dessa mesma "Bíblia de Jerusalém" ${ }^{34}$ apresenta um texto diverso, fugindo ao "negra" e preferindo "morena":

Sou morena, mas formosa, filhas de Jerusalém, como as tendas de Cedar e os pavilhões de Salma.

De um modo geral, e ao contrário do que, como vimos, ocorreu em outras línguas; parecem os tradutores de língua portuguesa empenhar-se sempre em evitar o vocábulo "negra". Prova-o, por exemplo, além da já-citada tradução de João Ferreira D'Almeida, a também clássica de Antônio Pereira de Figueiredo, ${ }^{35}$ feita em Lisboa, entre 1778 e 1790, a partir do texto latino da Vulgata:

Eu sou trigueira, mas formosa, ó filhas de Jerusalém, assim como as tendas de Cedar, como os pavilhões de Salomão.

34. Bíblia de Jerusalém, São Paulo, Ed. Paulus, 1987.

35. Aqui citada na edição de 1965, Rio de Janeiro, Ed. Barsa. 
O termo alternativo escolhido foi, desta vez, "trigueira" que parece tentar ser ainda mais eufemístico do que "morena" A mesma escolha de palavra vemos na tradução da Vulgata por Matos Soares: ${ }^{36}$

Eu sou trigueira, mas formosa, ó filhas de Jerusalém, I sou como as tendas de Cedar, / como os pavilhões de Salomão.

Atendo-se ao "morena" a tradução diretamente dos originais dirigida pelo Pontifício Instituto Bíblico de Roma ${ }^{37}$ rende-nos assim o texto:

Sou morena, porém, formosa, filhas de Jerusalém; morena como as tendas dos cedarenos, formosa como as cortinas de Salomão.

Outra tradução portuguesa, esta realizada pelo Centro Bíblico Católico, com base nos originais em hebraico, mediante, porém, a versão francesa dos monges de Maredsous (Bélgica), e revista por João José Pedreira de Castro, ${ }^{38}$ prefere o "morena" inovando apenas por preferir "bela" a "formosa" ou "aprazível":

Sou morena, mas sou bela, filhas de Jerusalém, como as tendas de Cedar, como os pavilhões de Salomão. (1981?).

36. Citado aqui cf. a edição publicada no Rio de Janeiro pela editora Gamma Editorial, s/d 37. São Paulo, Edições Paulinas, 1967.

38. $115^{\text {a }}$ edição, São Paulo, Editora Ave Maria, 1998. 
Outra tradução recente ${ }^{39}$ optou por "graciosa" mas insistiu no "morena":

Sou morena, porém graciosa, ó filhas de Jerusalém, como as tendas de Cedar, como os pavilhões de Salomão.

Uma edição mais popular, publicada em linguagem simples e atual, talvez para leitores menos letrados, ${ }^{40}$ estabeleceu a seguinte redação para o versículo:

Mulheres de Jerusalém, eu sou morena, porém sou bela. Sou morena escura como as barracas do deserto, como as cortinas do palácio de Salomão.

O que há de muito curioso nessa edição é que ela insere uma nota de rodapé entre "porém" e "sou bela" Nessa nota se lê simplesmente: "porém ou $e^{\prime}$ Embora tenham adotado a adversativa, os editores não se furtaram a advertir o leitor acerca da possível leitura do texto com uma aditiva. $O$ fato de se tratar de uma edição protestante da Bíblia provavelmente explica a existência de muitas notas como essa, revelando um grande zelo em alertar o leitor para as várias conotações possíveis do texto bíblico e evitando impor-lhe ou sugerir-lhe uma única como a "verdadeira" Mereceu essa atenção especial (que não se encontra em outras Bíblias da mesma editora) talvez por se tratar de edição destinada ao grande público, quiçá dotado de menor senso crítico e supostamente mais influenciável pelas idiossincrasias deste ou daquele tradutor.

39. Garmus, Ludovico (org.), Bíblia, Petrópolis, Ed. Vozes, 1986. A tradução do Cântico dos Cânticos é de Luís Stadelmann.

40. A Bíblia na Linguagem de Hoje, São Paulo, Sociedade Bíblica do Brasil, 1988. Esta edição, ao que parece, toma como base a tradução de João Ferreira D'Almeida, adaptando-a e parafraseando-a em linguagem simples e didática. 
A última edição brasileira da tradução de João Ferreira D'Almeida ${ }^{41}$ alterou ligeiramente sua fraseologia original:

Eu estou morena e formosa, ó filhas de Jerusalém, como as tendas de Quedar, como as cortinas de Salomão.

O que há de mais significativo nessa nova versão é o emprego do verbo "estar" em lugar de "ser" A peculiar e sutil diferença semântica entre esses verbos (desconhecida no latim - língua da Vulgata - e existente apenas no português e em muito poucos idiomas, como o italiano e o espanhol) foi observada com muita propriedade nesse texto, levando em conta uma interpretação sistemática do cântico bíblico. Realmente, o versículo seguinte nos revela que a camponesa não "é" negra ou morena (ou seja, a pele escura não é atributo inerente ao seu ser), mas apenas "está" morena pela ação dos raios solares (ou seja, a pele escura é uma característica acidental e transitória).

Aliando o verbo "estar" à aditiva "e", o texto em questão nos propicia, entretanto, uma leitura bastante diferente do versículo, pois transmite a idéia de que a camponesa considera seu bronzeado uma característica estética positiva, unindo-a sem conflito ao adjetivo "formosa" e dando mesmo a impressão de que a morenidade ou o estado moreno de sua pele foi cultivado e é a própria causa da formosura. Esse fraseado é por certo lisonjeiro para o público leitor de um país tropical como o nosso (e pode ter sido esse o motivo de sua adoção pelos revisores brasileiros), mas conflita frontalmente com os padrões estéticos vigentes na Antigüidade e está em antinomia com o versículo seguinte, no qual a protagonista procura justificar a cor de sua pele, como se fora algo indesejável, e pede ao amado que releve tal característica sua.

41. Citamos a $2^{\mathrm{a}}$ ed. revista e atualizada no Brasil, São Paulo, Sociedade Bíblica do Brasil, 1993. 
Singularmente, foi em uma edição popular da Bíblia em versos ${ }^{42}$ que encontramos a mais precisa escolha de palavras, com o verbo "estar" e o emprego da adversativa:

Estou bastante morena, porém, estou formosa, ó filhas desta cidade, Jerusalém amorosa, estou formosa igual tenda, as tendas lá de Quedar, e como aquelas cortinas de Salomão pra enfeitar.

Vemos que o poeta manteve o "morena" ${ }^{43}$ aumentado contudo pelo advérbio "bastante" que faz lembrar o "very dark" da Revised Standard Version. ${ }^{44}$ É provável, porém, que o acréscimo do advérbio tenha resultado apenas das necessidades métricas e rítmicas da versificação, sendo altamente duvidoso que o autor conhecesse a RSV ou tenha procedido a estudos mais profundos do texto original a ponto de dar a essa escolha de palavras algum sentido exegético especial.

É curioso observar que a quase totalidade das traduções em língua portuguesa evita cuidadosamente o adjetivo "negra" O mesmo não-acontece, como vimos, nas demais línguas. E poderíamos aduzir ainda mais exemplos, além dos já vistos. Em língua sueca, por exemplo, foi realizada a seguinte tradução: ${ }^{45}$

Svart är jag, dock är jag täck, I Jerusalems döttrar, lik Kedars hyddor, lik Salomos tält.

42. Rocha, Isnard, A Bíblia em Versos, $2^{\text {a }}$ ed., Atibaia, Ébano Editora, 1995.

43. Tudo indica que o reverendo Isnard tenha usado a tradução de João Ferreira de Almeida como base para a sua versificação.

44. Cf. supra p. 227 e nota 18.

45. Bibeln i överensstämmelse med den av konungen år 1917 gillade och stadfästa översättningen I elektronisk utgåva av Projekt Runeberg. Também este texto está disponível pela Internet, em: http://www.lysator.liu.se/runeberg/bibeln/ 
O tradutor sueco valeu-se do vocábulo "svart", com certeza cognato do alemão "schwarz" ${ }^{46}$ Qualquer dicionário de sueco ${ }^{47}$ atestará que essa palavra não apenas se traduz por "negro" mas ainda é usada em expressões como "svarta tavlan" (quadro-negro, nas escolas), ou "stå på svarta listan" (estar na lista negra), que atestam de modo inequívoco a sua clara conotação de "negro" e não exclusivamente "moreno"

Do mesmo modo tanto a tradução holandesa de 1750:

Ik ben zwart, doch liefelijk (gij dochteren van Jeruzalem!), gelijk de tenten van Kedar, gelijk de gordijnen van Salomo.

quanto a luterana, na edição de $1933:^{48}$

Zwart ben ik, maar liefelijk, gij dochters van Jeruzalem, gelijk de hutten van Kedar, gelijk de tapijten van Salomo.

empregam o termo "zwart", decerto outro cognato de "schwarz" e "svart", com o mesmo significado de "negro" 49

Em dinamarquês temos o seguinte texto: ${ }^{50}$

46. A raiz gótica é swarts, do germânico *swarta, cf. Wahrig, Gerhard, Deutsches Wörterbuch, München, Mosaik Verlag, 1966 (reed. revista 1986).

47. Por exemplo o do Swedish School Computer Network, disponível pela Internet no endereço http://www.nada.kth.se/skolverket/swe-eng.html

48. Ambas disponíveis na Internet em: http://www.omroep.nl/eo/bible/olb/ned/lut/passages.htm

49. Confirmá-lo-á qualquer dicionário de holandês, por exemplo: Cassell's Dutch Dictionary: Nederlands-Engels, $36^{\mathrm{a}}$ ed., Macmillan Publishing-Prisma Woordenboek: Het Spectrum BV.

50. Bibelen I elektronisk udgave af Søren Hornstrup genom Projekt Runeberg, disponível em http://www.lysator.liu.se/runeberg/dkbibel/ 
Jeg er sort, dog yndig, Jerusalems Døtre, som Kedars Telte, som Salmas Forhang.

Observamos a ocorrência do vocábulo "sort", igualmente significando "negro" como se pode verificar em qualquer dicionário dinamarquês, ${ }^{51} \mathrm{e}$ provavelmente também aparentado com "schwarz"

Em húngaro encontramos a seguinte tradução; ${ }^{52}$

Fekete vagyok, de szép, Jeruzsálem leányai; mint Kédár sátrai <és> Salamon szõnyegei.

E também a palavra "fekete" significa apenas "negro" conforme nos mostram os dicionários, ${ }^{53}$ aparecendo em expressões como "fekete piac" (mercado negro), "fekete mágia" (magia negra), "fekete özvegy" (viúva negra), "fekete lista" (lista negra), "fekete halál" (peste negra) e "fekete nyakkendô" ("black tie"), que evidenciam o seu sentido exato.

Em finlandês o texto é o seguinte: $:^{54}$

Minä olen musta, mutta ihana, te Jerusalemin tyttäret, kuin Keedarin teltat, kuin Salomon seinäverhot.

5l. E.g. o Travlang's Dictionary, agora disponível na Internet em: http://dictionaries.travlang.com/DanishEnglish/

52. Cf. Magyar Elektronikus Könyvtár, que se encontra disponível em: gopher://gopher.mek.iif.hu:7070/11/porta/szint/human/vallas/biblia

53. Como exemplo citamos o de Attila Vonyó, sob os auspícios do Szabad Szoftver Alapítvány, e disponível em: http://www.vein.hu/ vonyoa/szotar.htm http://tpri6l.gsi.de/htbin/szot_choose.sh

54. Esta tradução se encontra à disposição de todos na Internet, em: http://www.funet.fi/pub/doc/religion/christian/Bible/html/finnish/1933,38/ 
A palavra escolhida pelo tradutor foi "musta" que também significa "negra", conforme os dicionários, ${ }^{55}$ sendo empregada em expressões como "musta lista" (lista negra), "musta pörssi" (mercado negro) e "musta laatikko" (caixa-preta).

No Brasil, ao contrário, como vimos, preferiu-se sempre o "morena". Por que razão justamente a nação que é um "melting pot" étnico e que se jacta de ser uma "democracia racial" parece ter tanto medo de dizer "negro"? Pois até mesmo na linguagem do dia a dia percebemos que a maioria das pessoas evita esse termo, preferindo dizer, por exemplo, que "Fulano é escurinho" ou "é de cor" Apenas uma tradução mais recente, feita diretamente do original em hebraico, ${ }^{56}$ parece ser rara exceção, pois manteve o vocábulo "negra":

Sou negra, mas bela, filhas de Jerusalém, como as tendas de Cedar, como os pavilhões de Salmá.

Os tradutores, no entanto, inseriram a seguinte nota de rodapé, explicando o citado versículo; ${ }^{57}$

Negra: queimada pelo sol como costumam ser as guardiãs de vinhas (v. 6) e as pastoras de rebanhos ( $v$. 8). Embora devotada a trabalhos humildes, a esposa faz notar, com graça feminina, que ela não deixa de ser elegante e atraente.

Com isso se vê que, embora os tradutores brasileiros tenham mantido a fraseologia original, não-deixam de reconhecer que o sentido pretendido para a

\footnotetext{
55. E.g. o dicionário Eurodicautom do European Commission Translation Service (@ECSC-ECEAEC, Brussels-Luxembourg, 1996, 1997, 1998), disponível em: http://www2.echo.lu/edic/

56. Charbel, Antônio, e Salvador, Joaquim (org.), LEB (Liga de Estudos Bíblicos), A Bíblia, $3^{\text {a }}$ ed., São Paulo, Ed. Abril Cultural, 1982. O Cântico dos Cânticos foi traduzido por Estevão Bettencourt.
}

57. Idem, v. 4, p. 292, nota 5. 
palavra "negra" é, realmente, o de "morena" e ainda que se não tenham atrevido a emendar o texto, fizeram questão de assinalar, em nota de rodapé, que as palavras de Salomão não contêm um comentário de caráter étnico. ${ }^{58}$

Uma outra edição dessa mesma tradução ${ }^{59}$ oferece uma nota de rodapé ainda mais elucidativa, embora cause alguma espécie em razão do seu linguajar "ideologizante":

\section{A linguagem corrente distinguia as meninas} burguesas, chamadas brancas, $e$ as camponesas trabalhadoras chamadas negras.

A menção a "burgueses" na sociedade hebraica de 2.500 (ou mais) anos atrás despertará o riso a qualquer historiador. E a contraposição das "burguesas" às camponesas "trabalhadoras" parece saber a um certo quê de discurso esquerdista. À parte disso, a nota confirma a preocupação de, uma vez aceito o termo "negra" esclarecer ao leitor, e sem a menor dubiedade, que não se trata de alusão a etnias.

Vimos, assim, ainda que de modo muito breve, a origem bíblica da inscrição na madonna de Tindari e o tratamento que ao longo dos séculos the deram os tradutores nos vários idiomas modernos. Seja mencionado, todavia, que a nossa pesquisa não foi exaustiva e completa. É evidente que não-consultamos todas as traduções existentes da Bíblia nos diversos idiomas (trabalho esse tão-colossal que seria para nós virtualmente impossível). Por nos falecerem o tempo e os recursos bibliográficos necessários, tampouco pudemos acompanhar minuciosamente todas as

58. A fidelidade ao texto original se explica, quem sabe, por ser esse um caso excepcional no Brasil de uma edição "erudita" da Bíblia, rica em comentários e notas críticas. As edições mais simples, com finalidades meramente "pastorais", talvez tenham tido que tratar o texto com maior liberdade, traduzindo pelo sentido mais que pela literalidade, deixando menos para a ilação do leitor, a fim de ser mais acessíveis ao público geral, o qual muitas vezes - e sobretudo em nossa terra revela escasso preparo para a leitura e interpretação de textos literários mais complexos. Aceitemos pelo menos, então, em defesa dos tradutores e editores nacionais da Bíblia, que essa também possa ter sido uma das razões para quase sempre terem evitado o termo "negra"

59. São Paulo, Edições Loyola, 1983. 
edições e revisões sucessivas de cada tradução, a fim de estudar a evolução do versículo estudado - o que seria de rigor numa investigação verdadeiramente científica do assunto. E, por não interessar ao escopo que ora nos move, abstivemonos por completo de ventilar outras particularidades presentes no texto que examinamos (como por exemplo a referência aos "pavilhões" ou "cortinas de Salomão", assim referidas na Vulgata e na Septuaginta, bem como em muitas traduções tradicionais, mas corrigida em algumas outras para "pavilhões de Salmá" — tribo localizada na Arábia - com base em estudos recentes que consideram equivocada a alusão ao rei hebreu).

De todo modo, acreditamos que, com base nas informações que pudemos coligir e até aqui expor, é-nos lícito oferecer já algumas conclusões:

1 A inscrição na madonna negra de Tindari é uma citação da Vulgata (Cântico dos Cânticos, 1:5);

2 Tanto a Vulgata quanto a Septuaginta utilizam a palavra "negra" para traduzir esse versículo;

3 A Vulgata e a Septuaginta estão de acordo com o original hebraico, que também emprega o termo "negra" nesse versículo;

4 - Muitas das traduções modernas preferiram substituir o "negra" pelo "morena" pois esse é o sentido que melhor condiz com os versículos seguintes, que sugerem uma mulher queimada de sol, e não-pertencente à etnia negra. Não pode ser inferida do versículo nenhuma intenção de aludir a preconceitos étnicos, seja nos textos originais, seja em qualquer das traduções modernas. Percebe-se no entanto uma especial preocupação, nas edições mais recentes do texto bíblico, de evitar uma possível e enganosa conotação racista na tradução desse versículo. Essa preocupação parece não ser tão-marcante em edições mais antigas, até o século XIX, o que revela ser bem contemporâneo esse afã de expurgar os textos antigos de qualquer possível menção a idéias que firam o reinante espírito de "political correctness" de nossos tempos; ${ }^{60}$

60. Tem-se tornado conspícua a influência do "political correctness" na redação do texto bíblico em edições recentes. A "Revised English Bible" de 1989 tratou de banir das escrituras todas as 
5 Enquanto a Vulgata opta pela adversativa ("negra mas formosa"), a Septuaginta empregou uma conjunção aditiva ("negra e formosa"). ${ }^{61} \mathrm{~A}$ maioria das traduções modernas parece preferir a adversativa, que de fato está em melhor consonância com o sentido geral do versículo no contexto em que ele se insere;

6 Quanto ao "nigra sum sed formosa": pode-se em suma concluir que não se trata de uma expressão preconceituosa ou racista, mas sim de uma alusão de origem bíblica à tez escura das pessoas que trabalham ao sol e que, pela rudeza de sua condição humilde, apresentam a pele maltratada e anti-estética pela atuação dos raios solares. A inscrição na madonna negra tem um sentido puramente religioso e não exprime preconceito étnico, o qual seria inteiramente incompatível com o verdadeiro sentimento de qualquer religião, judaica ou cristã.

Para quem prefere, por fim, entender os cantares de Salomão como livro de inspiração religiosa sob a forma alegórica de um poema de amor, são possíveis as interpretações mais rebuscadas, na forma de uma alegoria. Rica e variada é a bibliografia exegética das escrituras. Citemos, como exemplo apenas textualmente e abstendo-nos de qualquer observação pessoal ${ }^{62}$ - a obra de Matthew Henry que, desde que publicada em $1706,{ }^{63}$ tem sido reputada o mais famoso e respeitado comentário integral da Bíblia:

passagens consideradas "sexistas", substituindo a palavra "homem" por "pessoa" toda vez que se não referisse expressamente a uma determinada personagem do sexo masculino. Tem sido também noticiada nos jornais a indignação de grupos feministas com o fato de que o texto da Bíblia se refere a Deus no masculino. Não ousando operar uma mudança de sexo no Altíssimo, os editores da "Revised English Bible" mantiveram o masculino, mas diplomaticamente deixaram de grafar com maiúscula o pronome "ele" quando referido a Deus.

61. Vide, porém, a nota 12 supra e o texto correspondente, à p. 223.

62. Cabe aqui novamente a observação feita à nota 13 supra.

63. Existem edições recentes, e.g.: Henry, Matthew, Commentary on the whole Bible, Nashville, Tennesee, T. Nelson, 1997. 
She asserts her own comeliness notwithstanding (v. 5): I am black, but comely, black as the tents of Kedar, in which the shepherds lived, which were very coarse, and never whitened, weather-beaten and discoloured by long use, but comely as the curtains of Solomon, the furniture of whose rooms, no doubt, was sumptuous and rich, in proportion to the stateliness of his houses. The church is sometimes black with persecution, but comely in patience, constancy, and consolation, and never the less amiable in the eyes of Christ, black in the account of men, but comely in God's esteem, black in some that are a scandal to her, but comely in others that are sincere and are an honour to her. True believers are black in themselves, but comely in Christ, with the comeliness that he puts upon them, black outwardly, for the world knows them not, but all glorious within, Ps. 45:13. St. Paul was weak, and yet strong, 2 Co. 12:10. And so the church is black and yet comely; a believer is a sinner and yet a saint; his own righteousnesses are as filthy rags, but he is clothed with the robe of Christ's righteousness. The Chaldee Paraphrase applies it to the people of Israel's blackness when they made the golden calf and their comeliness when they repented of it.

Podemos, por fim, acrescentar que a idéia de inscrever semelhante citação bíblica na madonna negra de Tindari não foi casual e nem tão-inusitada como se pode pensar. Apesar de ser hoje pouco conhecido da maioria das pessoas, aquele versículo teve importância nada negligenciável na liturgia cristã tradicional, sendo a frase "nigra sum sed formosa" empregada como antífona ao Salmo 121 no Officium Beatae Mariae e assim recitada ad vesperas desde o primeiro dia após a festa da purificação até as vesperae do sábado antes do primeiro domingo do advento, com exceção do dia da festa da anunciação: ${ }^{64}$

64. Texto latino citado aqui conforme: The Primer, or Office of the Blessed Virgin Marie, in Latin and English Antuérpia, Arnold Conings, 1599 (reed. facsimilar: Rogers, D. M. (org.), English 
ANT: Nigra sum.

PSALMUS [121]:

II Laetatus sum in his, quae dicta sunt mihi:

(et rel.)

II Gloria Patri, et Filio: et Spiritui sancto. Sicut

erat in principio, et nunc, et semper: et in saecula

saeculorum, Amen. Alleluia.

ANT: Nigra sum, sed formosa filiae Hierusalem:

ideo dilexit me Rex, et introduxit me in cubiculum suum.

Não cabe aqui intentar uma discussão sobre o seu significado litúrgico, mas parece evidente que o escultor da imagem ou os responsáveis pelo santuário de Tindari estavam bem familiarizados com a referida antífona e acharam natural incluíla como lema ou epígrafe. ${ }^{65}$

Tendo sido tão-conhecido e reputado liturgicamente importante, esse trecho do Cântico dos Cânticos, já desde a Idade Média cantado em cantus planus, inspirou muitos compositores a musicá-lo. O francês Jean L'Héritier (c.1480 - depois de 1552), discípulo de Josquin des Près, compôs um motete a cinco vozes sobre o "nigra sum sed formosa" Giovanni Pierluigi da Palestrina (1525-1594), igualmente, compôs um motete "Nigra Sum" a cinco vozes, influenciado pela obra de L 'Héritier, e em 1590 publicou sua Missa "Nigra Sum" Tomás Luis da Victoria (1548-1611), tido como um dos maiores compositores espanhóis de música vocal sacra, também compôs um motete "Nigra Sum" a seis vozes. E ainda o grande Claudio Monteverdi (1567-1643) pôs em música o Vespro In II. Vesperis in Festis Beatae Mariae Virginis, que naturalmente inclui a antífona "nigra sum sed formosa" 66

Recusant Literature, 1558-1640, v. 262, Ilkley/Yorkshire/London, The Scolar Press, 1975). Na verdade, o Breviarium Romanum manteve essa antífona inalterada até o nosso século.

65. As imagens negras da madonna já há tempos têm sido associadas ao versículo 1:5 do Cântico dos Cânticos. Cf. bibl. cit. supra notas 1 e 2 .

66. Todas essas obras, incluindo uma versão em cantus planus e uma outra de autoria de Andreas De Silva (1475/80-c.1530), estão disponíveis em gravação ADD (originalmente analógica, mas remixada digitalmente) no CD Palestrina Masses (selo Gimell, n. 454903-2), com a interpretação dos 
De tudo isso tiramos ao menos uma lição importante: por mais apto e zeloso que seja o tradutor, as armadilhas da tradução são inumeráveis e muito sutis: uma conjunção, uma vírgula, um advérbio ou a simples escolha entre palavras sinônimas são pequenos detalhes capazes de comprometer muito seriamente o texto e induzir ilações que deturpem o sentido originalmente pretendido pelo autor. Vimos que as diferentes traduções até mesmo de um pequeno versículo da Bíblia podem emprestar-lhe uma grande diversidade de conotações. Por isso, jamais recorramos a uma tradução se o texto original estiver disponível (salvo se a língua de origem for absolutamente inacessível para a comum das pessoas em nosso meio cultural, qual por exemplo o chinês, japonês, russo ou hebraico), principalmente quando se tratar de leitura técnica ou de caráter acadêmico, e de todo modo nem pensemos em citar traduções como base para um trabalho científico digno desse nome. A esse propósito dizem bem os italianos: traduttore, traditore.

À luz dessas conclusões, voltemos a considerar o incidente com o vestibular na Universidade de Mato Grosso. Citando o texto bíblico, o examinador mato-grossense bem poderia tentar exculpar-se pela cincada que cometeu, não sendo fantasioso imaginar que, se o advogado que estivesse defendendo a Universidade em um eventual processo tomasse conhecimento dos fatos que acabamos de expor, por sem dúvida trataria de utilizá-los em seu arrazoado - e talvez com êxito, pois que juiz não-hesitaria ante a perspectiva de condenar uma frase que se encontra na Bíblia?

The Tallis Scholars sob a regência de Peter Phillips. A mesma gravação da missa de Palestrina, acompanhada do motete de L 'Héritier e da versão em cantus planus se encontra no álbum de 4 CDs The Palestrina 400 Collection (Gimell 454890-2), lançado em homenagem aos 400 anos da morte de Palestrina. Também em 1994 foi lançada em gravação digital (DDD) uma interpretação do motete de Palestrina pelo grupo Pro Cantione Antiqua, sob a regência de Bruno Turner, no CD Canticum Canticorum Salomonis (Hyperion Records, London, CDA66733). Também o Hilliard Ensemble gravou o Canticum Canticorum em DDD, num álbum de 2 CDs do selo Capitol, n. 61 168, lançado em 1995. E ainda o Ensemble William Byrd sob a regência do maestro O'Reilly gravou essa mesma obra em DDD, em CD lançado em 1998 pelo selo Jade, n. 28337. O Vespro de Monteverdi existe em gravação DDD de 1996 com o Concerto Italiano na regência de Rinaldo Alessandrini, no CD Musica Sacra (selo Opus 111, n. 30-150). Além dessas, outras gravações podem estar disponíveis no mercado, e a lista que apresentamos é meramente exemplificativa, não sendo tampouco seletiva por critério algum de qualidade ou preferência. 
Mas será que realmente o autor da questão tinha esse versículo da Bíblia em mente quando redigiu as infelizes orações para a prova? Parece-nos muito difícil acreditar nessa possibilidade, embora pareça igualmente improvável que ele tivesse uma intenção consciente de externar um preconceito racista, com animus iniuriandi contra os representantes da raça negra. Temos a impressão de que tudo não deve ter passado de um muito aziago deslize, um tropeção inconsciente muito provavelmente carente de dolus malus. A questão foi decerto preparada por algum dedicado professor de português que, absorto nas suas análises sintáticas e semânticas, nem se apercebeu da tolice que escrevia. É bem possível que a oração tenha sido impensadamente copiada das frases exemplificativas de alguma antiga gramática portuguesa. Mas é, todavia, significativo esse deslize, como um ato-falho que revela muita verdade oculta da nossa gente. Longe de ser uma democracia racial, o Brasil ainda tem em seu povo sentimentos raciais muito tristemente arraigados e que se revelam nesses atos-falhos, como quando alguém repete, com cândida inocência, que "Fulano é um preto, mas tem alma branca". Há não muito tempo ouvimos de uma senhora conhecida a seguinte resposta, quando lhe indagaram se tinha algum preconceito contra os negros: "Eu não! Coitadinhos, eles não têm culpa de serem pretos..." São atitudes profundamente racistas como essa que precisam ser eliminadas, e infelizmente não é tão-simples fazê-lo apenas com artigos de leis.

Com certeza a UFMS deve "desculpas à sociedade", como expressou o seu magnífico reitor. Mas será que o referido professor de português e autor da questão, seja ele quem for, realmente merece ser apenado com três anos de reclusão, sem direito a fiança, por causa de um lastimável deslize? Parece-nos exagero, embora caiba à Justiça essa decisão. Na condição de professor universitário, no entanto, julgamos descabida a pretensão do Grupo Tez de pleitear a anulação da questão. Ainda que condenável no seu conteúdo ideológico, a questão, do ponto de vista estrito de uma avaliação de língua portuguesa, foi bem concebida (é evidente que todas as cinco afirmações da questão são gramaticalmente corretas; não há possível dúvida quanto ao gabarito da prova). Uma eventual sanção de penalidade contra o autor da questão não deveria implicar uma sanção de nulidade contra a mesma, o que seria muito injusto para com os candidatos - muitos deles certamente negros - que, ainda que ressentidos do pensamento racista do examinador, tenham resolvido corretamente a questão de gramática e seriam prejudicados injustamente com a sua anulação.

São Paulo, dezembro de 1998. 